\title{
Towards Spiritually Sensitive Social Work in a Multi Ethnic Western World
}

\author{
Venkat Pulla \\ Faculty of Health Sciences, Australian Catholic University, Australia
}

\begin{abstract}
Progressive secularisation of western societies connotes casualization of spiritual care and where presented it appears to be highly tentative. An acid test to confirm the futility of our current aptitude in social work skill emerges prominently as we deal with minority and ageing populations in western societies. Irrespective of culture into which people are born into there appears to be a recognition that spiritual concerns commence early in one's development, when life is full of zest, vigour and vitality and as a result of preoccupation with zestful life these spiritual concerns remain on a back burner. Whichever journey that a social worker partakes in, and whom is spiritually sensitive, it is not only productive for the client but is also especially rewarding for the social worker as it initiates their personal inward reflective journey. The concepts in this paper are conceived and situated from the western world's perspective, but it is possible to resonate equally with social work agenda for the East. In this paper I aim to deal with how we inform ourselves about concerns of spiritual nature amidst the challenges and opportunities that surround us as we live amongst a multitudinous ethnic western society. Furthermore, I will be discussing the efficacy of the strengths based approach in social work practice within the context of building a spiritual social work framework.
\end{abstract}

Keywords Spirituality, Social Work and Spiritual Social Work, End of Life, Palliative

\section{Introduction}

The world nowadays is recognising an increased amount of people that are able to cope, hope, act, anticipate, prevent, promote and transcend. There is an assumption that these pointers suggest growing awareness of religion and spirituality as two integral sources of inner and outer strengths to deal with adversity, illness ageing and disability (Canda, 2013). Clearly the central theme of human life on this planet appears to be one of coping, and resilience and that of relying on one's own inner strengths (Pulla, 2013). In western nations the conception of spirituality is not embedded within the definitions of mainstream 'culture' and with a great deal of sadness we admit that social work practice has also remained aloof and cold to this vital and pervasive force of spirituality within our societies that assists coping and resilience. As a result to propose an appropriate client centred service to ethnic groups in multitudinous ethnic society social workers are expected to deal with their own prejudices and reticence at challenging the user's beliefs. This is both a challenge and an opportunity for modern social work. In the recent years there has been an increase in the interest in research on religion/spirituality and mental health. That religion and spirituality can play a positive role in coping abilities and can impact physical and mental health among the ageing, while improving the physical occurrences including cardiovascular, neuroendocrine, and immune function that has been established in a number of studies. Reviews strongly suggest that religion and mental health are positively correlated (Frame, 2003; Koenig, 2007). The studies in the west are predominantly focusing on the impact of Judeo-Christian practices and the importance of meditation.

Favourable associations with numerable measures of religious and spiritual involvement assists in many problems such as suicide risk, building well-being, working with clients from that show drug and alcohol abuse, criminal behaviour, depression, and social adjustments, and emotional stability. Deriving from a strengths approach insofar to mention that good social work practice is to recognise elements such as religion and spirituality or concurrently that offer clients a meaning and purpose in their lives. Participation in spiritual activities builds resilient responses to illnesses and adversity, enhances greater engagement, improved self-care, invites logistical and social supports from family and friends and builds a sense of sacred transpersonal support (Canda, 2013). Occasionally western social workers have addressed spirituality in their writing but their effort has not been consistent and has remained sporadic. Some social workers feel comfortable to associate 
religion and spirituality, while others wish to perceive the distinction made between spirituality and religion. There are social workers who understandably decide to be different to the moralistic and or conservative values associated with religion that may conflict with their own views and that of what is purported to be scientific, secular and professional in social work. Additionally, our focus in the west is predominantly clinical as we draw our theoretical knowledge from classical psychoanalysis and behavioural modification schools that reject religion and consider it to be an illusion and unscientific. Such thinking has considerably influenced the professional writing in modern social work and has also allowed the profession of social work to acquire a dichotomy of academic respectability on one hand and to become scientific on the other (Seinfeld, 2012).

Over the years, the demographics in the western nations have also significantly altered. Predominance of mono cultural and ethnic groups is on the wane in with these nations. In addition, the demographics appear to be changing in the rest of the world. At present there are over twenty countries that have more than one ethnic and cultural group that is represented in their demographics. To mention a few countries these include: Australia, Argentina, Canada, Mexico, United States, United Kingdom, Continental Europe, Bulgaria, Netherlands, Germany, Philippines, India, Indonesia, Japan, Malaysia, Mauritius, Singapore and South Korea. Predominately, the Islamic national states in the United Arab Emirates [UAE] and other national states such as Qatar, Sultanate of Oman and Saudi Arabian nations have huge expatriate communities living and working in these countries other than adhering to Islamic faiths. Communion, ritual and celebration of spirituality of the working migrant inhabitants is regarded as a private affair in these countries. Certainly there are no temples, synagogues and churches in the UAE and Saudi Arabia dissimilar in the western world.

In the west these particular migrations of a temporary or permanent nature have presented challenges and present considerable opportunities to the profession of social workers to practice cross cultural competencies. People migrating from one nation to the other convey their culture alongside them with its two distinct elements of ethnicity, which are religion and spirituality. Thus, western nations have commenced to employ and the adoption of terms such as, multicultural societies. Throughout the past three decades mainstream models of social work in the west were obliged to develop its cross cultural diversity practice. This provides substantial opportunity for the social work profession to engage with ethnicities other than English or white or dominant Christian religious background communities this has escalated. Social events and situations that require social work presence has anticipated that individual social workers are required to progress beyond their own cultural frameworks. Practice areas such as bereavement within a family, terminal illness, immigration and resettlement of refugee in second and third countries and so forth, are clearly required to have a greater understanding of the cultural contexts of the client's community. In contemporary western countries, social work issues such as family planning, family life, child protection, domestic harmony call for display and use of social work abilities, cross cultural sensitivities and a degree of sensitivity of the religion and spirituality of the client communities. Late Jeffrey Seinfeld, more recently observed that 'there was much greater appreciation of the therapeutic value of spirituality and religion in the lives of its clients' (Seinfeld, 2012, p. ?).

The term 'spirituality' comes from its root word, the spirit that is something meaningful, central and the core of all human activity (reference is needed here because of quotation?). It could begin with feelings expressed as being wholesome; feeling powerful, energetic and hopeful. In its nascent form one's spirit is something deep within a human being that directs, accelerates motivates to survive and thrive at the same time. The effects of spirituality can be validated by professional observations. Deep human perceptions and human values such as love, justice, peace, right action and right conduct, the display and presence of which in human beings constructs them as innately spiritual. For copious people including the west, God, Buddha, Bodhisattvas, arch angels, ancestors, helping spirits, vital energies, qi, kundalini shakthi, sufi saints, have all existed for a long time side by side providing a wide range of faith and belief systems for the human kind on this planet. Some of these faiths and beliefs have taught humanity prayers, meditation and ritual including requests and petitions in prayers particularly in situations of suffering (Canda, 2013) In all probability it would not be an exaggerated observation if in the last two decades, people have progressed to be more open to concepts such as finding their life's purpose, meaning and beginning to recognise and grasp on to their spiritual characteristics. The 'Spirit' seems to be the suggestion of the day in any form, remaining formless, invisible, sounding abundance of energy and is generally regarded as a source providing sustenance of life on this planet.

There is a suggestion that in social work teaching and training we need to incorporate knowledge and practice from themes such as mindfulness, gratitude, forgiveness, radical acceptance, hitting rock bottom, redemption and surrendering the ego to a higher power. Seinfeld (2012) relates some of these themes towards familiar western psychodynamic concepts and the implications for western clinical practice. Commensurate in addition to this, is also a greater recognition in current society that spirituality and religion are not synonymous. In reference, understanding stems from the premise that we regard the human being and/or the rest of creation as composed not only of matter, but of something immaterial, something invisible, and something beyond our present knowledge. There is always more to what we can perceive with our senses and know with our reason. Thus the meaning of spirituality is that it is a term which encompasses everything that we cannot see directly with our eyes, or directly perceive by all other senses and to know by our mere reason. That is spirituality in its basic meaning. Canda made an eloquent definition of spirituality as the 'human quest for personal meaning and mutually 
fulfilling relationships among people, the non-human environment, and for some, God' (Canda, 2013, p.?). Spirituality can also be deciphered from one's attitudes towards or their approach to life. Numerous people nowadays are searching for an overarching meaning and purpose in life. There are many seekers that crave for and seek morally fulfilling relationships with self and others, their relationship with nature and the universe. Therefore a spiritual approach may be viewed as a transformation or a process through which the different aspects of life such as physical, emotional, occupational, intellectual and rational may be integrated more meaningful. To practice loving-kindness, forgiveness, compassion, trust, reverence, wisdom, faith and sense of oneness that is being sought out in the world today, this is a clear indication for the dawn of a spiritual era into which entry of social work ought to be smooth and pervasive.

This paper suggests that spirituality is something that we all contain, irrespective of our involvement in formal religion and whether we recognise it as such. Spirituality is neither a peripheral nor an alternative for those with a particular frame of mind. We all have spirituality whether we desire one or not, whether we are religious or not. Spirituality is more about whether or not we can sleep with a clear conscience at night than whether or not we go to church, mosque, temple or synagogue. It is not about dogmas, it is about simple natural universal regulation we may call them natural universal laws. Irrespective of whether or not we allow ourselves to be consciously shaped by any explicit religious idea, we act in ways that leave us either healthy or unhealthy. Many people who claim neither spirituality nor religious pursuit appear to be following a virtuous path in their own way. Their actions demonstrate their convictions and their core belief in human values of pursuing truth; of conducting oneself non-violently; of caring for the fellow human being; and of looking after nature. Having said that, it is equally correct to suggest that the concept of spirituality is inclusive and overlaps with that of religion, but unlike spirituality, to belong to a religion is an option exercised by a number of people in our societies today. By default being born, baptised, named by elders and parents through sacred religious rites and traditions may hold keys to their religious identity, but seldom reveals one's spiritual beliefs. Thus, in social work practice many questions are warranted before confirming an identity to a client of either a religious or a spiritual nature. Social work practice is set around a number of values, such as non-violence, peace and interconnectedness of all beings with a view to build a sustainable world. Social work is about community wellbeing and empowerment, human dignity and social justice, 'rebalancing economic, social political and environmental arenas of social organisation and construction' (Carrington, 2010, p. ?) Therefore, it is not an overstatement if I argued that social work is intrinsically spiritual and that if we tease its core elements we would find the centrality of the human spirit or 'spirituality'. In social work practice as well as in our own personal lives we encounter multiple situations in which the interventions of medicines, surgery doctors having decent private medical cover do not seem to provide the outcomes that are being sought. In such cases when occurences are beyond the control of the scientific utilitarian observation and where the dominant paradigms do not necessarily assist us, our prudence seems to accept other methods of recognising knowledge and ways of knowing beyond the dominant to be valid (Carrington, 2010) Our knowledge and training in social work does not seem to provide all the answers to our problems and that of our clients. Therefore, a growing spiritual urge for a number of social work practitioners is innate in their recognition, realisation and reverence to things beyond the existing dominant paradigm of the scientific and the secular. Defining the scope of spiritual enquiry in this manner allows us to move beyond orthodoxy and ritual of the religion to reach more people. In the western world, social work is situated in a rational, secular, highly individualist, materialistic framework despite its strong foundations in values such as goodness; faithfulness, godliness, holiness, piousness and devoutness. In the west, people are beginning to recognise and understand karma as well.

\section{Beginning with a Cultural Approach}

Contemporary social work and human services are merely beginning to adapt and attune to the growing demands of a culturally diverse world in the west. The world views of culturally diverse clients differ from the world of members of the dominant society. Whilst culturally diverse clients attribute disorders to causes quite alien from western diagnosis, and then definitions of healing and wholesomeness of life are different from conventional social work the profession uncovers new challenges. What begins as a journey into understanding the cultural background of the client assists the social worker to appreciate some of the deeply held spiritual notions and beliefs of the client culture. Promotion of inclusiveness and client centred approaches are central to social work. Therefore, adoption of broad frameworks of cultural sensitivity is imperative. Culture undergoes change as it intersects with all variables of gender, race, geography, race and class (Graham, Bradshaw, and Trew, 2010). In modern social work a void of a great nature exists as attempts to locate both religion and spirituality within the framework of social work are nascent and apologetic. Simultaneously, a growing number of Social Work practitioners are interested in applying a spiritual approach through training interventions (Canda, Nakashima, \& Furman, 2004). Mel Gray (2008) takes a broad view of spirituality as a motivated characteristic of the social work's desire to make life better for others through ethical practice and suggests that spirituality is an important aspect of the literature of coping with death and dying and dealing with trauma and is of primal importance when dealing with people of an Indigenous origin (Gray, 2008). 
International Federation of Social Workers (IFSW) 2004 statement acknowledges and compels social workers to strive for the recognition of the dignity, worth and the uniqueness of all human beings, the assumption, identification and recognition of strengths and potential of all human beings and an appreciation and respect for diversity in relation to 'race', culture, religion, ethnicity, linguistic origin, gender, sexual orientation and differential abilities. The Global Standards for the Education and Training of the Social Work Profession (IASSW and IFSW, 2004) mention 'spiritual factors' as amongst the types of knowledge that qualified social workers require in understanding human development and behaviour (IASSW and IFSW, 2004: 6).

\section{The Context of Spirituality}

Over a long period of time, a myopic view of our humanity allowed us to concentrate on the physical, psychological and social but grossly avoided the mention of that search for meaning and value which makes up the spiritual element of human living. When we use the term 'care' the elements of compassion, respects for individual beliefs and their values would provide the over encompassing umbrella. Social work with the aged clients compels us to stop for the moment, contemplate and begin our journey as practitioners with the elderly. Unknowingly, a number of social workers perform their job spiritually. For instance, as they treat the person with respect; when they listen to their stories in a meaningful way; when the client perceives that that the social worker has further treated them as a whole person within the context of their life; values and beliefs. Thus, these are the right directions for the professional to cultivate their spiritual framework. From a strengths based practice perspective, when we recognise that all human beings have an innate capacity for receiving health, welfare and self-righting, which is a drive, and a life force that has the capacity to provide healing and transformation (Wieck, 1992), when we recognise that almost continually, that people know intuitively what is right for them (Pulla, 2012). A Spiritual framework for the social worker commences with the practice of nonjudgmental attitude; placing what is best and doing what is best for the client. The framework provides a personal, friendly, empathic, and accepting relationship that creates opportunities for healing, transformation, regeneration, and resilience. Conveying a positive orientation to foresee the future and transmit hope from the client's perspective will prove to be useful for healing and helping (Pulla, 2012). Thus, it is possible to find the seeds for health and self-righting, even in maladaptive responses or patterns of behaviour, since individuals may be trying to satisfy some need for respect, connection, affection, or control. It is possible for social work to incorporate spirituality as a dimension in the bio-psycho-social assessment and treatment planning process. The opening conversations as part of building an assessment relationship, as Hogde (2004) suggested they ought to identify and describe responses and reactions of caregivers (including social workers) to spiritual beliefs and expressions and the impact of these reactions on client that we are serving. Evidently, it is important for social workers to gain an understanding of the diverse expressions of spirituality with and without relationship to religion. Such an approach is rather inclusive and will allow social work to demonstrate increased awareness of spirituality and its impact on client coping with suffering, loss, trauma, injustices and assist the social worker to meaningfully partake in the attempts to heal, endure and assist the clients to reach their goals. Constructing a spiritual framework into social work practice also provides the social worker an opportunity to self-examine personal self-assessment and reflection on one's own spirituality and its impact on their social work practice.

\section{A Strengths Approach}

The spiritually sensitive social work provides the ways that practitioners and clients to seek a sense of meaning, purpose, and connectedness as they move forward in their goals and aspirations, augment their strengths and resources, and work towards overcoming personal obstacles and environmental blocks and the gaps in resources. Clients have cultural and personal stories and indegnious peoples lore that social workers must be ready to hear in order to understand the deep sources of strengths in moments of adversity and crisis. In my view the following additional questions will help:

What have people learned and understand about themselves, others, and their world? (Early \& GlenMaye, 2004; Saleebey, 2006, 2009)

What personal qualities, traits, talents, and virtues reside in these people?

How do some of them display during crises and after trauma?

How do survivors discover their inner strengths, utilize the ones that they know, and also develop new strengths? (Early \& GlenMaye, 2004; Saleebey, 1997; Weick et al., 1989).

What is that they hold with a sense of pride? (Wolin and Wolin (1993) as the "survivor's pride" in overcoming the odds.

What are their personal and familial narratives of survival and redemption? Do they provide strategies, tools, symbols, and metaphors for rebound?

Can we re-discover the community and its different resources, which possibly all of us including clients frequently overlooked during presenting crisis?

What family traditions, rituals, and the combination of strengths of their nuclear and extended family members do these client families continue to present? (Early \& GlenMaye, 2004)

Certainly it would provide a broad spectrum world view with which the social worker could assist the client with the personal hopes and begin to reshape their dreams (Pulla, 2012) Through utilizing the strengths approach social workers have an opportunity to create and enable spiritual 
niches that bring additional comfort to the clients wellbeing. To build spiritually sensitive social work practice an understanding of spirituality as a process of human life and development that focuses on the search for a sense of meaning, purpose, morality, and well-being in relationship with oneself, other people, other beings, and that the universe is very important.

The following sets of questions are equally important. As practitioners we need to quickly gain some understanding of the deeper persuasions that give out client spiritual inclinations. What persuasions do they belong to? (Animistic, atheistic, nontheistic, polytheistic, theistic, or any other way) How do they engage in a sense of transcendence (experienced as deeply profound, sacred, or transpersonal)? How do they partake in private and public expression of their religion or spirituality? Is it healthy or unhealthy manifestations? Does it lead to self- harming or injurious to others?

Hogde (2011) suggests spiritual interventions as therapeutic strategies that incorporate a spiritual or religious dimension as a central component of the intervention and his rubric takes into consideration: (1) client preference, (2) evaluation of relevant research, (3) clinical expertise, and (4) cultural competency.

Furthermore, the purpose of this paper is to offer guidelines for social workers using spiritual interventions and utilising a cultural competency framework. Social work as a profession that is concerned with eliciting and working with client preferences as this is central to the core ethical principle of social work. Consideration of client preference increases client engagement and results in outcomes that ensure client self-determination. Determination of client preference regarding the use of spiritual interventions needs to be viewed as a recurring process. In the first instance, social workers need to determine clients' interest in spirituality and religion, the latter being the vehicle through which spirituality is commonly expressed (Gallup \& Jones, 2000). This can be accomplished by conducting a brief spiritual assessment. Hodge, made this rather simple and effective (Hodge, 2004). Even a preliminary question such as "I was wondering if spirituality or religion is important to you" (Hodge, 2003). A question like that would allow social workers understand if the client is open to spirituality as it is classified a 'personal topic' in the west. Consequently, some clients are hesitant to trust practitioners with this aspect of their being (Richards \& Bergin, 2000), a stance that is understandable given the lack of relevant training many practitioners have received (Sheridan, 2009). Whatever the case is, it is important to raise this question right from the start of the intervention as it assists social workers to work more inclusively and allows social work to protect clients' rights to ask for the use of spiritual interventions, or to refrain from delving into spirituality, during the subsequent conversations.

It is important to recognise that religion and spirituality develop across the lifespan and both are inherently social-psychological cognitive phenomena. By the same token both religion and spirituality are related to affect emotions and as social work interventions aim to work with the affect and emotions, it would be important to integrate religion/spirituality into counselling interventions, social workers need to develop competency in assessment of clients and this paper recommends a qualitative open-ended approach to understanding client's spiritual/religious history. Hogde (2006) cautions about the need to obtain informed consent as a process rather than a one-time event as clients may initially indicate they are uninterested in spiritual interventions, perhaps due to concerns that practitioners may not respect their spiritual beliefs and values. Later on, they may change their minds after interacting with, observing, building trust, and testing practitioners sufficiently to risk incorporating the spiritual dimension. This is a risk that social work practitioners ought to be willing to undertake while ensuring self-determination by client is respected throughout the process, from engagement to termination.

Hodge, (2011) points out another important guideline such as, research on those spiritual interventions that are relevant to the client's problem. Regardless of the worldview used to assess evidence, the aim is to develop a working understanding of what is required in each client's context. One of the important tenets of strengths based practice is not to assume that one size fits all. Care and caution is required particularly in the context and in relation to people belonging to minorities for examples, Hindus, Buddhists or even Muslims in western societies. It would be important to recognise that each religion and spiritual framework generates its own culturally distinct worldviews (Richards \& Bergin, 2000). A central issue in the selection of spiritual interventions requires clinical expertise in the field.

Spiritual interventions should only be used when sufficient preparation and research is undertaken by the social worker. Research also recommends consideration of sufficient understanding and experience using each intervention (Canda \& Furman, 2010). There appears to be some sort of unanimity amongst social workers today that the clients do have a right to expect that social workers have some degree of expertise in the interventions they implement. When discussing spirituality with clients, it is important to focus on solving clients' problems. A substantial degree of overlap exists between therapy and spiritual direction, a practice designed to increase a person's intimacy with God or the Transcendent (Ganje-Fling \& McCarthy, 1991).

By knowing about religion or gaining some central ideas about spirituality social workers do not replace the functions of the priest or the pundit. It is an advantage to gain the knowledge so that should collaborative interventions are required the professional is prepared. When social work practitioner world views are different from that of the clients we have an opportunity to develop interventions that relate to cross cultural competencies. In many western nations including Australia standards for Cultural Competence in Social Work Practice suggest that social workers should 
exhibit cultural competency in their work with people from other than their own or dominant traditions. In a manner analogous to cultural competence, spiritual competence can be understood as a process where practitioners develop expertise in three mutually related arenas:

- A growing awareness of their own value-informed spiritual worldview and its assumptions, limitations, and biases;

- An empathic understanding of the client's spiritual worldview; and

- An ability to design and implement interventions that resonate with their client's spiritual worldview (Hodge \& Bushfield, 2006, p.).

Thus, spiritual competence is not a static entity but a dynamic set of attitudes, knowledge, and skills related to various spiritual traditions that can be developed over time (Sue \& Sue, 2008). Equally, spiritual competence is to be viewed as an evolving construct and for many experienced practitioners consider that this could even take as much part of their life time to pick up the bare essentials.

Developing an awareness of one's own worldview plays an important role in managing what might be called "spiritual countertransference" (Frame, 2003; Genia, 2000; Hodge, 2002a; Miller, 2003). When working with individuals from a different spiritual worldview, practitioners' unresolved personal issues may unconsciously affect their interactions with clients. For instance, practitioners who have rejected their own family's faiths and traditions may consciously or unconsciously oppose spiritual worldview of the client. Conscious and unconscious and verbal and nonverbal expressions, innuendos and cues of the client give out the practitioner's unpreparedness or lack of preparation or lack of appreciation. Any disapproval on either side can have a negative therapeutic relationship. Frame (2003) suggests a good amount of self-exploration to manage anticipated and unanticipated reactions and it is a notable idea to raise it in professional supervision. It is challenging to discover the potential of one's own transformation. This mode of learning necessitated by the client's needs allows the social work practitioner to visit the continuously evolving and changing personal meaning-value systems, worldviews, and lifestyles. Such a process expands the possibility of change in aspects of the practitioner's personality as a result of inward analysis, and dawn of new wisdom would lead to a personal yet spiritual social work framework. Transcendence and personal growth and restructuring one's own personal and professional views is not new to Asian cultures, however this has received only slight attention in western frameworks. The relevance and meaning of personal transformation is self-evident, when stressful situation turn chronic and beyond individual personal capacities. In such situations, personal transformations appear to allow and construct the stressful situations of pain bearable and less threatening. One does not have to be a Zen Master to achieve this stage of transcendence. Agood beginning with an enlightened awareness of the need to transform and a heightened activity and persuasion to arrive at a spiritual framework would pave way especially for practitioners and clients already in some form of seeking spiritual answers in their situations. It is recommended that practitioners are open to their own transformation so that they can be of some assistance in everyday hassles and even major life events of the clients, and their families. This process is different from cognitive reframing; this is about personal transformation and is proactive rather than reactive. Cognitive reframe can typically occur in an encounter with a specific problematic situation, while personal transformation is typically an ongoing, holistic change process. It would be instructive to carefully examine the different types of personal transformation notwithstanding the fact that in some cases, the differences between worldviews can be extreme. Thus, developing an awareness of the strengths and limitations of one's own worldview helps in the process of developing an empathic understanding of culturally different spiritual worldviews. Practitioners need not necessarily agree with the worldviews affirmed by their clients. They should, however, be able to develop a sensitive and empathic understanding of these alternative constructions of reality and as Sue and Sue (2008) suggest that it is important to understand one's own limitations and articulate one's own worldview in this process.

\section{Conclusion}

Although the meaning of spirituality and faith differ when drawn from religious or non-religious knowledge bases, they remain as matters of sensitivity, emotion and are held personal and also have far reaching potential to become pervasive in the modern world. This paper urges that practitioners to consider development of a spiritual framework in social work to bring forward more enduring outcomes and effects sought to improve and ameliorate the lives of people that they come in contact with. Beliefs and practices seem to impact within a wide range of areas such as child care, communication norms, death and burial rituals, diet, family relations, financial practices, gender interactions, marital relations, medical care, recreation, schooling, and work habits (Richards \& Bergin, 2000). Conclusively, at the heart of spiritual practice is the ethical competence which cannot be minimised at any degree within a culture. In the final analysis the return of the spiritual focus into social work appears to the author as postmodern entry. Moreover, the author abides by a strong belief that for the present, and the current trends in the modern world allows an opportunity for the social work activist with spiritual framework to re-present an agenda that will energise our societies and nations applying greater holistic and humanitarian groundwork. 


\section{REFERENCES}

Canda, E. R., (2013). Chronic Illness and Spiritual transformation. In Saleebey, D (Editor), The Strengths Perspective in Social Work (6th ed.). Boston: Pearson.

Canda, E. R., \& Furman, L. D. (2010). Spiritual diversity in social work practice: The heart of helping (2nd ed.). New York: Oxford University Press.

Canda, E. R., Nakashima, M., \& Furman, L. D. (2004). Ethical considerations about spirituality in social work: Insights from a national qualitative survey. Families in

Carrington, A, (2010). Spiritual paradigms: A response to Concerns within Social Work in relation to the Inclusion of Spirituality. Journal of Religion \& Spirituality in Social Work: Social Thought, 29: 4, pp-300-320

Early, T. J., \& GlenMaye, L. F. (2004). Valuing Families: Social Work Practice with Families from a Strengths Perspective. Social Work, 45(2), 118-130.

Frame, M. W. (2003). Integrating religion and spirituality into counseling. Pacific Grove, CA: Brooks/Cole.

Gallup, G. J., \& Jones, T. (2000). The next American spirituality: Finding God in the twenty- first century. Colorado Springs, CO: Victor.

Ganje-Fling, M. A., \& McCarthy, P. R. (1991). A comparative analysis of spiritual direction and psychotherapy. Journal of Psychology and Theolgy 19, 103-117.

Genia, V. (2000). Religious issues in secularly based psychotherapy. Counseling and Values, 44, 213-221

Graham, R, J., Bradshaw, C. and Trew, J, L. (2010). Cultural 'Considerations for Social Service Agencies Working with Muslim Clients', Social Work, 55(4), pp.337-346.

Gray, M. (2008).Viewing spirituality in social work through the lens of contemporary social theory. British Journal of Social Work, 38, 175-196.

The Global Standards for the Education and Training of the Social Work Profession ASSW and IFSW, 2004 www.iassw-aiets.org/global-standards-for-social-work-education-a nd-training

Hodge, D. R. (2003). Spiritual assessment: A handbook for helping professionals. Botsford, CT: North American Association of Christians in Social Work.

Hodge, D. R. (2004). Spirituality and people with mental illness: Developing spiritual competency in assessment and intervention. Families in Society, 85, 36-44.

Hodge, D. R. (2006). A template for spiritual assessment: A review of the JCAHO requirements and guidelines for implementation. Social Work, 51, 317-326.

Hodge, D. R., \& Bushfield, S. (2006). Developing spiritual competence in practice. Journal of Ethnic and Cultural Diversity in Social Work, 15(3/4), 101-127.
Hodge, D. (2011): "Using spiritual interventions in practice: developing some guidelines from evidence-based practice." Social Work 56.2149

Koenig, H. G. (2007). Spirituality in patient care (2nd ed.). Philadelphia: Templeton Foundation Press.

Miller, G. (2003). Incorporating spirituality in counseling and psychotherapy. Hoboken, NJ: John Wiley \& Sons.

Neimeyer, R.A, (1995). An appraisal of constructivist psychotherapies, in M.J.

Mahoney (Ed.), Cognitive and constructive psychotherapies (pp. 163-194). New York: Stringer

Pulla, V., Shatte, A. \& Warren, S. eds .,(2013). Perspectives on Coping and Resilience, New Delhi: Authorpress, Authorpress Global Network

Pulla, V., (2013) 'Contours of Coping and resilience: the front story In Pulla, V., Shatte, A. \& Warren, S. eds. Perspectives on Coping and Resilience, New Delhi: Authorpress, Authorpress Global Network

Pulla, V., Chenoweth, L., Francis, A., Bakaj, S. eds ,(2012). Papers in Strengths Based Practice, New Delhi: Allied Publishers

Pulla, V., 'What are Strengths based Practice all about? In Pulla, V., Chenoweth, L., Francis, A., Bakaj, S. eds,(2012). Papers in Strengths Based Practice, New Delhi: Allied Publishers.

Richards, S., \& Bergin, A. (Eds.). (2000). Handbook of psychotherapy and religious diversity. Washington, DC: American Psychological Association.

Saleebey, D. (Ed.). (2006). The Strengths Perspective in social work practice (4th ed.). Boston: Allyn \& Bacon.

Saleebey, D. (Ed.). (2009). The Strengths Perspective in social work practice (5th ed.). Boston: Allyn \& Bacon.

Seinfield,J, (2012). Spiritualty in Social Work Practice: Clinical Social Work Journal, 40- pp-240-244, Springer.

Sheridan, M. (2009). Ethical issues in the use of spiritually based interventions in social work practice; what are we doing and why? Journal of religion and Spirituality in Social Work: Social Thought, 28(1\&2), 99-126

Sue, D., \& Sue, D. (2008). Counseling the culturally diverse: Theory and practice (5th ed.). Hoboken, NJ: John Wiley \& Sons.

Weick, A., Rapp, C., Sullivan, W. P., \& Kisthardt, W. (1989). A Strengths Perspective for Social Work Practice. Social Work, 34(4), 350 .

Weick, A. (1992). Building a strengths perspective for social work. In D. Saleebey (Ed.), The strengths perspective in social work practice. White Plains, NY: Longman.

Wilber, K(1999), The collected works of Ken Wilber ( Vol.3), Boston: Shambhala

Wolin, S., \& Wolin, S. (1993). The resilient self: How survivors of troubled families rise above adversity. New York: Villard. 